termination of the bath (8 patients) were the most common triggers. Interictal EEGs obtained in 22 patients showed epileptiform abnormalities over temporal regions in $9(41 \%)$. Brain MRIs in 15 patients and CTs in 2 were normal except for cortical atrophy in 1 and mesial temporal sclerosis in 1. Treatment with AEDs, mainly carbamazepine, in 16 patients prevented seizure recurrence; avoidance of the precipitating factor prevented seizures in the remainder. (Yalcin AD, Toydemir HE, Forta $\mathrm{H}$. Hot water epilepsy: clinical and electroencephalographic features of 25 cases. Epilepsy \& Behav August 2006;9:89-94). (Respond: Dr A Destina Yalcin, Selcuklar Sokak, Ozlem Apt, 51/14, 34335 Akatlar, Istanbul, Turkey).

COMMENT. Hot water epilepsy is a benign form of reflex epilepsy, typically complex partial with temporal lobe localization, and occurring most frequently in children and young adults, males predominantly. Reports of HWE are most prevalent in India and Turkey, where sitting to bathe and pouring hot water over the head from a bowl are common customs.

Seizures precipitated by very hot water-head baths $\left(40-50^{\circ} \mathrm{C}\right)$, a regional religious custom, were reported in 279 patients between 1980-83 in Bangalore, Southern India (Satishchandra $\mathrm{P}$ et al. Epilepsia 1988;29:52-56). Clinical features were similar to those reported in the Turkish clinic patients: ages ranged from 8 months to 58 years, $28 \%$ below 6 years; males predominated $2.65: 1$; only $7 \%$ had a history of febrile seizures; $67 \%$ had $\mathrm{HW}$-induced complex partial seizures; and $30 \%$ had spontaneous non-reflex epilepsy also. A family history of epilepsy was positive in $22 \%$, but HWE in only $7 \%$. In treatment, the avoidance of the hot water stimulus to the head was supplemented with AEDs. The mechanism was unclear. A hot-air stimulus to the scalp failed to induce attacks. In infants, a febrile seizure induced by the hot water might explain some attacks, but was not confirmed by body temperature recordings. A specific tactile reflex seizure may occur in response to combing the hair in children with absence epilepsy (Millichap; personal observation of a case of repeated eye fluttering and seizure induction by tapping the scalp). Two cases of HWE with CPS, in association with focal cortical dysplasia, and localized to the left parietal region in 1, are reported by Grosso S et al. (Brain Dev 2004;26:490-493; Ped Neur Briefs 2004;18:70).

Lennox WG (in Epilepsy and Related Disorders, Boston; Little, Brown; 1960;357-370) prefers the term "sensory precipitation" to reflex epilepsy, for seizures induced by touch, smell, taste, hearing, and sight. He cites a case recounted by Hughlings Jackson (1886) of a boy who had falling (astatic or myoclonic) seizures if his head or face was unexpectedly touched. Lennox records failure of seizure induction "by non-painful hot or cold skin applications."

\title{
LEVELS OF ANTIEPILEPTIC DRUGS AND THE KETOGENIC DIET
}

Introduction of the ketogenic diet did not change the plasma levels of antiepileptic drugs in an open study of 51 children (mean age 6.6 years) with refractory epilepsy studied at Karolinska University Hospital, Stockholm, Sweden. (Dahlin MG, Beck OML, Amark PE. Plasma levels of antiepileptic drugs in children on the ketogenic diet. Pediatr Neurol July 2006;35:6-10). (Respond: Maria G Dahlin MD PhD; E-mail: maria.dahlin@karolinska.se). 